\title{
PARAMETRIC ANALYSIS AND MULTI OBJECTIVE OPTIMIZATION OF CUTTING PARAMETERS IN TURNING OPERATION OF AISI 4340 ALLOY STEEL WITH CVD CUTTING TOOL
}

\author{
M. Adinarayana ${ }^{1}$, G. Prasanthi ${ }^{2}$, G. Krishnaiah ${ }^{3}$ \\ ${ }^{1}$ Assistant Professor, Department of mechanical Engineering, Sir Vishveshwaraiah Institute of Science \& Technology \\ Angallu, Madanapalli \\ ${ }^{2}$ Professor, Department of Mechanical Engineering, JNTUA College of Engineering, JNTUA, Anantapuramu \\ ${ }^{3}$ Professor (retire), Department of Mechanical Engineering, SVU College of Engineering, S.V.University, Tirupati
}

\begin{abstract}
Modern manufacturers, seeking to remain competitive in the market, rely on their Manufacturing engineers and production personnel to quickly and effectively set up manufacturing processes for new products. This paper presents the multi response optimization of turning parameters for Turning on AISI 4340 Alloy Steel. Experiments are designed and conducted based on Taguchi's $L_{27}$ Orthogonal array design. This paper discusses an investigation into the use of Taguchi parameter Design and Regression analysis to predict and optimize the Surface Roughness, Metal Removal Rate and Power Consumption in turning operations using CVD Cutting Tool. The Analysis of Variance (ANOVA) is employed to analyze the influence of Process Parameters during Turning. This paper also remarks the advantages of multi-objective optimization approach over the single-objective one. The useful results have been obtained by this research for other similar type of studies and can be helpful for further research works on the Tool life and Vibration of tools etc.
\end{abstract}

Keywords: Turning, Ra, MRR, PC, Taguchi, Anova etc...

\section{INTRODUCTION}

The production of super alloys, high hard and smart materials have become extremely essential to satisfy the design requirements for critical equipments, aerospace and defense industries. The machining of such materials has always been a great challenge before the production engineer [1].

EN24 is a medium-carbon low-alloy steel and finds its typical applications in the manufacturing of automobile and machine tool parts. Properties of EN24 steel, like low specific heat, and tendency to strain-harden and diffuse between tool and work material, give rise to certain problems in its machining such as large cutting forces, high cutting-tool temperatures, poor surface finish and built-up-edge formation. This material is thus difficult to machine [2]. The proper selection of cutting tool material has also different advantages such as reducing the manufacturing cost and lead time, machining more difficult materials, moving to unmanned machining operations, improving surface integrity and achieving high metal removal rates. Coating provides Improved lubrication at the chip-tool and work-tool interface to reduce friction and consequently to reduce the temperatures at the cutting edge. Coated carbides tools ensure higher wear resistance, lower heat generation and lower cutting forces, thus enabling higher cutting speeds than uncoated carbides [3].
The huge amount of money spent on any one class of cutting tool is spent on turning. Therefore, from view point of cost and productivity, modeling and optimization of turning process are extremely important for the manufacturing industry [4]. The difficulties in optimization operations made the determination of cutting parameters an important and complex case [5]. To maintain the desired quality of machining products, to reduce the machining cost and to improve the machining effectiveness, it is vey important to select the optimal machining parameters when the Machine tools are selected. Thereafter, an Optimization Technique is used to search the optimal control parameter setting for the desired response [6]. Optimization of Machining parameters increases the utility for machining economics and also increases the product quality to greater extent [7].

The objective of this experimental investigation is to ascertain the effects of cutting speed, feed rate, and depth of cut on Surface Roughness, Material Removal Rate and Power Consumption in Turning of AISI 4340 medium Alloy steel. The survey showed that there are many papers in the field of turning parameters optimization, but there is a lack in studies of the Response Power Consumption Optimization in Turning operation which is very important aspect in machining operation. Power Consumption plays vital role. One its cuts down the Cost per product, secondly the environmental impact 
by reducing the amount of carbon emissions that are created in using by electrical energy and finally the minimization of Power Consumption. Design of experiment techniques, i.e. Taguchi's technique have been used to accomplish the objective. L27 orthogonal array used for conducting the experiments. And ANOVA technique is employed to analyze the percentage contribution and influence of Process Parameters.

\section{MATERIALS AND METHODS:}

\subsection{Specification of Work Material:}

The work material used for the present study is AISI 4340 alloy steel. The chemical composition of the work material is shown in Table 1.

\begin{tabular}{|l|l|l|l|l|l|l|l|l|}
\hline \multicolumn{7}{|c|}{ Table 1: Specification of work material } \\
\hline Element & $\mathrm{C}$ & $\mathrm{Si}$ & $\mathrm{Mn}$ & $\mathrm{S}$ & $\mathrm{P}$ & $\mathrm{Cr}$ & $\mathrm{Ni}$ & $\mathrm{Mo}$ \\
\hline Composition\% & 0.38 & 0.15 & 0.60 & 0.040 & 0.035 & 0.70 & 1.65 & 0.20 \\
\hline
\end{tabular}

\subsection{Process Parameters}

\begin{tabular}{|l|l|l|l|}
\hline \multicolumn{4}{|c|}{ Table 2: Process parameters and their levels } \\
\hline Level & $\begin{array}{l}\text { Speed }(\mathrm{s}) \\
(\mathrm{rpm})\end{array}$ & $\begin{array}{l}\text { Feed rate(f) } \\
(\mathrm{mm} / \mathrm{rev})\end{array}$ & $\begin{array}{l}\text { Depth of cut(d) } \\
(\mathrm{mm})\end{array}$ \\
\hline 1 & 740 & 0.09 & 0.15 \\
\hline 2 & 580 & 0.07 & 0.10 \\
\hline 3 & 450 & 0.05 & 0.05 \\
\hline
\end{tabular}

\subsection{Taguchi Method}

The Taguchi experimental design method is a well-known, unique and powerful technique for product or process quality improvement. It is widely used for analysis of experiment and product or process optimization. Taguchi has developed a methodology for the application of factorial design experiments that has taken the design of experiments from the exclusive world of the statistician and brought it more fully into the world of manufacturing [13]. Traditional experimental design methods are very complicated and difficult to use. Additionally, these methods require a large number of experiments when the number of process parameters increases. In order to minimize the number of experiments required, Taguchi experimental design method, a powerful tool for designing high-quality system. This method uses a special design of orthogonal arrays to study the entire parameter space with minimum number of experiments [2]. Taguchi strategy is the conceptual framework or structure for planning a product or process design experiment.

\subsection{Analysis of Variance (ANOVA)}

Analysis of variance (ANOVA) is a statistical method for determining the existence of differences among several population means. While the aim of ANOVA is the detect differences among several populations means, the technique requires the analysis of different forms of variance associated with the random samples under study- hence the name analysis of variance. The original ideas analysis of variance was developed by the English Statistician Sir Ronald A. Fisher during the first part of this century. Much of the early work in this area dealt with agricultural experiments where crops were given different treatments, such as being grown using different kinds of fertilizers. The researchers wanted to determine whether all treatments under study were equally effective or whether some treatments were better than others.

ANOVA is used to determine the influence of any given process parameters from a series of experimental results by design of experiments and it can be used to interpret experimental data. Since there will be large number of process variables which control the process, some mathematical model are require to represent the process. However these models are to be develop using only the significant parameters which influences the process, rather than including all the parameters.

\section{EXPERIMENTATION AND MATHEMATICAL}

\section{MODELING:}

The experiment is conducted for Dry turning operation of using AISI 4340 Alloy steel as work material and CVD as tool material on a conventional lathe PSG A141. The tests were carried for a $500 \mathrm{~mm}$ length work material. The process parameters used as spindle speed (rpm), feed $(\mathrm{mm} / \mathrm{rev})$, depth of cut $(\mathrm{mm})$. The response variables are Surface roughness, material removal rate and power consumption, The experimental results were recorded in Table 3. Surface roughness of machined surface has been measured by a stylus (surf test SJ201-P) instrument and power consumption is measured by using Watt meter. Material removal rate is calculated by following formula.

$$
\text { MRR = (Initial weight }- \text { final weight }) / \text { Density } x \text { Time }
$$


Where Density of EN 24 material $=7.85 \mathrm{gm} / \mathrm{cc}$

Surface roughness need to the minimum for good quality product

(Lower is the better)

The surface roughness, $\mathrm{Ra}$

$$
\operatorname{Min} R_{a}(s, f, d)
$$

Minimizing $R a=0.237 S^{0.389} f^{-0.392} d^{0.305}$

MRR need to be maximum for increasing the production rate (Higher is the better)

The material removal rate, $\mathrm{MRR}$ $\operatorname{Max} \operatorname{MRR}(\mathrm{s}, \mathrm{f}, \mathrm{d})$

$$
M R R=0.004 S^{0.988} f^{0.004} d^{0.672}
$$

Power consumption need to be minimum for reducing the cost of finished product,

(Lower is the better)

The Power consumption, PC

$$
\text { Min PC (s, f, d) }
$$

$$
\text { Minimizing } P C=0.052 S^{0.995} f^{0.469} d^{0.0970}
$$

Ranking of various process parameters for the desired conditions of surface roughness, material removal rate and power consumption shown in Tables 4, 5 and 6. And the

\begin{tabular}{|c|c|c|c|c|c|c|}
\hline S.No & $\begin{array}{c}\text { Speed (s) } \\
(\text { rpm) }\end{array}$ & $\begin{array}{c}\text { Feed (f) } \\
(\mathbf{m m} / \mathbf{r e v})\end{array}$ & $\begin{array}{l}\text { Depth of } \\
\text { cut, }(\mathrm{mm})\end{array}$ & $\begin{array}{c}\text { Surface } \\
\text { Roughness Ra } \\
(\mu \mathrm{m})\end{array}$ & $\begin{array}{c}\text { Material } \\
\text { removal rate } \\
\left(\mathrm{mm}^{3} / \mathrm{min}\right)\end{array}$ & $\begin{array}{c}\text { Power } \\
\text { Consumed } \\
(\mathrm{kW})\end{array}$ \\
\hline 1 & 740 & 0.09 & 0.15 & 2.8422 & 0.75 & 9.3416 \\
\hline 2 & 740 & 0.09 & 0.1 & 4.7161 & 0.394737 & 11.75489 \\
\hline 3 & 740 & 0.09 & 0.05 & 2.8118 & 0.266667 & 10.3628 \\
\hline 4 & 740 & 0.07 & 0.15 & 4.1796 & 0.4 & 10.5261 \\
\hline 5 & 740 & 0.07 & 0.1 & 4.8156 & 0.674157 & 8.74391 \\
\hline 6 & 740 & 0.07 & 0.05 & 4.6386 & 0.514286 & 7.73641 \\
\hline 7 & 740 & 0.05 & 0.15 & 5.2697 & 0.580645 & 9.164832 \\
\hline 8 & 740 & 0.05 & 0.1 & 4.1441 & 0.45283 & 7.66528 \\
\hline 9 & 740 & 0.05 & 0.05 & 3.9445 & 0.514286 & 5.3281 \\
\hline 10 & 580 & 0.09 & 0.15 & 2.73 & 0.761905 & 7.286254 \\
\hline 11 & 580 & 0.09 & 0.1 & 5.8497 & 0.461538 & 5.01187 \\
\hline 12 & 580 & 0.09 & 0.05 & 2.8809 & 0.48 & 6.17281 \\
\hline 13 & 580 & 0.07 & 0.15 & 4.8045 & 0.643432 & 7.848 \\
\hline 14 & 580 & 0.07 & 0.1 & 4.2464 & 0.571429 & 6.72485 \\
\hline 15 & 580 & 0.07 & 0.05 & 3.733 & 0.45 & 8.766383 \\
\hline 16 & 580 & 0.05 & 0.15 & 6.985 & 0.638298 & 5.445271 \\
\hline 17 & 580 & 0.05 & 0.1 & 4.3915 & 0.633803 & 4.361176 \\
\hline
\end{tabular}
percentage contributions of various process parameters on response variables such as surface roughness, material removal rate and power consumption were shown in Tables 7, 8 and 9.

Table 3: Experimental data and results for 3 parameters, corresponding Ra, MRR and PC for CVD tool 


\begin{tabular}{|c|c|c|c|c|c|c|}
$\mathbf{1 8}$ & 580 & 0.05 & 0.05 & 3.9445 & 0.327273 & 5.12973 \\
\hline $\mathbf{1 9}$ & 450 & 0.09 & 0.15 & 3.4964 & 0.461538 & 7.659078 \\
\hline $\mathbf{2 0}$ & 450 & 0.09 & 0.1 & 3.7343 & 0.164384 & 4.970542 \\
\hline $\mathbf{2 1}$ & 450 & 0.09 & 0.05 & 1.972 & 0.338028 & 7.3297 \\
\hline $\mathbf{2 2}$ & 450 & 0.07 & 0.15 & 5.4475 & 0.474308 & 3.792101 \\
\hline $\mathbf{2 3}$ & 450 & 0.07 & 0.1 & 3.9944 & 0.645161 & 4.56132 \\
\hline $\mathbf{2 4}$ & 450 & 0.07 & 0.05 & 2.518 & 0.116732 & 5.37698 \\
\hline $\mathbf{2 5}$ & 450 & 0.05 & 0.15 & 5.1373 & 1.929825 & 6.42373 \\
\hline $\mathbf{2 6}$ & 450 & 0.05 & 0.1 & 2.6061 & 0.098361 & 5.61887 \\
\hline $\mathbf{2 7}$ & 450 & 0.05 & 0.05 & 2.8618 & 0.106572 & 3.709838 \\
\hline
\end{tabular}

Table 4: Response Table for Signal to Noise Ratios for Ra

\begin{tabular}{|c|c|c|c|}
\hline Level & Speed(S) & Feed(f) & Depth of Cut(d) \\
\hline 1 & -10.517 & -12.447 & -9.981 \\
\hline 2 & -12.505 & -12.424 & -12.447 \\
\hline 3 & -12.181 & -10.333 & -12.776 \\
\hline Delta(max-min) & 1.988 & 2.115 & 2.795 \\
\hline Rank & 3 & 2 & 1 \\
\hline
\end{tabular}

Table 5: Response Table for means for Ra

\begin{tabular}{|c|c|c|c|}
\hline Level & Speed(S) & Feed(f) & Depth of Cut(d) \\
\hline 1 & 3.530 & & \\
\hline 2 & 4.396 & 4.365 & 3.256 \\
\hline 3 & 4.151 & 4.264 & 4.278 \\
\hline Delta(max-min) & 0.866 & 3.448 & 4.544 \\
\hline Rank & 3 & 0.917 & 1.287 \\
\hline
\end{tabular}

Table 5: Response Table for Signal to Noise Ratio for MRR

\begin{tabular}{|c|c|c|c|}
\hline Level & Speed(S) & Feed(f) & Depth of Cut(d) \\
\hline 1 & -10.516 & -7.647 & -10.397 \\
\hline 2 & -5.405 & -6.859 & -8.172 \\
\hline 3 & -6.288 & -7.703 & -3.639 \\
\hline Delta(max-min) & 5.111 & 0.844 & 6.757 \\
\hline Rank & 2 & 3 & 1 \\
\hline
\end{tabular}

Table 6: Response Table for means for MRR

\begin{tabular}{|c|c|c|c|}
\hline Level & Speed(S) & Feed(f) & Depth of Cut(d) \\
\hline 1 & 0.4817 & 0.5869 & 0.3460 \\
\hline 2 & 0.5520 & 0.4988 & 0.4552 \\
\hline
\end{tabular}




\begin{tabular}{|c|c|c|c|}
\hline 3 & 0.5053 & 0.4532 & 0.7378 \\
\hline Delta(max-min) & 0.0703 & 0.1337 & 0.3918 \\
\hline Rank & 3 & 2 & 1 \\
\hline
\end{tabular}

Table 7: Response Table for Signal to Noise Ratio for PC

\begin{tabular}{|c|c|c|c|}
\hline Level & Speed(S) & Feed(f) & Depth of Cut(d) \\
\hline 1 & -14.54 & -15.08 & -16.09 \\
\hline 2 & -15.79 & -16.64 & -15.93 \\
\hline 3 & -18.85 & -17.46 & -17.15 \\
\hline Delta(max-min) & 4.31 & 2.38 & 1.22 \\
\hline Rank & 1 & 2 & 3 \\
\hline
\end{tabular}

Table 8: Response Table for means for PC

\begin{tabular}{|c|c|c|c|}
\hline Level & Speed(S) & Feed(f) & Depth of Cut(d) \\
\hline $\mathbf{1}$ & 5.494 & 5.872 & 6.657 \\
\hline $\mathbf{2}$ & 6.305 & 7.120 & 6.601 \\
\hline $\mathbf{3}$ & 8.958 & 7.766 & 7.499 \\
\hline Delta(max-min) & 3.465 & 1.894 & 0.897 \\
\hline Rank & $\mathbf{1}$ & $\mathbf{2}$ & $\mathbf{3}$ \\
\hline
\end{tabular}

Table 7: ANOVA for the response surface roughness (Ra)

\begin{tabular}{|l|c|c|c|c|c|}
\hline \multicolumn{1}{|c|}{ SOURCE } & DOF & $\begin{array}{c}\text { SUM OF } \\
\text { SQUARES }\end{array}$ & $\begin{array}{c}\text { MEAN OF } \\
\text { SQUARES }\end{array}$ & F RATIO & $\begin{array}{c}\text { \% OF } \\
\text { CONTRIBUTION }\end{array}$ \\
\hline Speed(S) & 2 & 3.590962 & 1.7954809 & 1.557132 & 13.7285501 \\
\hline Feed(F) & 2 & 4.549644 & 2.2748221 & 1.972841 & 17.393674 \\
\hline DOC(D) & 2 & 8.315008 & 4.1575039 & 3.605597 & 31.7889771 \\
\hline SXF & 4 & 0.342662 & 0.0856655 & 0.074293 & 1.31002538 \\
\hline SXD & 4 & 2.63119 & 0.6577975 & 0.570475 & 10.0592617 \\
\hline FXD & 4 & 6.727423 & 1.6818557 & 1.45859 & 25.7195053 \\
\hline ERROR & 8 & 9.224555 & 1.1530694 & & 100 \\
\hline TOTAL & 26 & 26.15689 & & & \\
\hline
\end{tabular}

Table 8: ANOVA for the response Material removal rate (MRR)

\begin{tabular}{|l|c|c|c|c|c|}
\hline SOURCE & DOF & $\begin{array}{l}\text { SUM OF } \\
\text { SQUARES }\end{array}$ & $\begin{array}{l}\text { MEAN OF } \\
\text { SQUARES }\end{array}$ & F RATIO & $\begin{array}{l}\text { \% OF } \\
\text { CONTRIBUTION }\end{array}$ \\
\hline Speed(S) & 2 & 0.023041 & 0.0115203 & 0.054739 & 1.73986563 \\
\hline Feed(F) & 2 & 0.083111 & 0.0415555 & 0.197452 & 6.2759712 \\
\hline DOC(D) & 2 & 0.735871 & 0.3679354 & 1.748256 & 55.5679469 \\
\hline SXF & 4 & 0.109602 & 0.0274004 & 0.130194 & 8.2763776 \\
\hline SXD & 4 & 0.24736 & 0.0618401 & 0.293835 & 18.678971 \\
\hline
\end{tabular}




\begin{tabular}{|l|c|c|c|c|c|} 
FXD & 4 & 0.125288 & 0.0313219 & 0.148827 & 9.46087847 \\
\hline ERROR & 8 & 1.683668 & 0.2104585 & & \\
\hline TOTAL & 26 & 1.324272 & & & 100 \\
\hline
\end{tabular}

Table 9: ANOVA for the response Power Consumption (PC)

\begin{tabular}{|l|c|c|c|c|c|}
\hline SOURCE & DOF & $\begin{array}{l}\text { SUM OF } \\
\text { SQUARES }\end{array}$ & $\begin{array}{l}\text { MEAN OF } \\
\text { SQUARES }\end{array}$ & F RATIO & $\begin{array}{l}\text { \% OF } \\
\text { CONTRIBUTION }\end{array}$ \\
\hline Speed(S) & 2 & 59.10341 & 29.55171 & 7.220334 & 66.75899 \\
\hline Feed(F) & 2 & 16.6795 & 8.339748 & 2.037641 & 18.83997 \\
\hline DOC(D) & 2 & 4.548608 & 2.274304 & 0.555678 & 5.137782 \\
\hline SXF & 4 & 1.759423 & 0.439856 & 0.107469 & 1.987318 \\
\hline SXD & 4 & 3.999739 & 0.999935 & 0.244313 & 4.517819 \\
\hline FXD & 4 & 2.44184 & 0.61046 & 0.149153 & 2.758128 \\
\hline ERROR & 8 & 32.74276 & 4.092845 & & \\
\hline TOTAL & 26 & 88.53252 & & & 100 \\
\hline
\end{tabular}

\section{Main Effect Plot Analysis:}

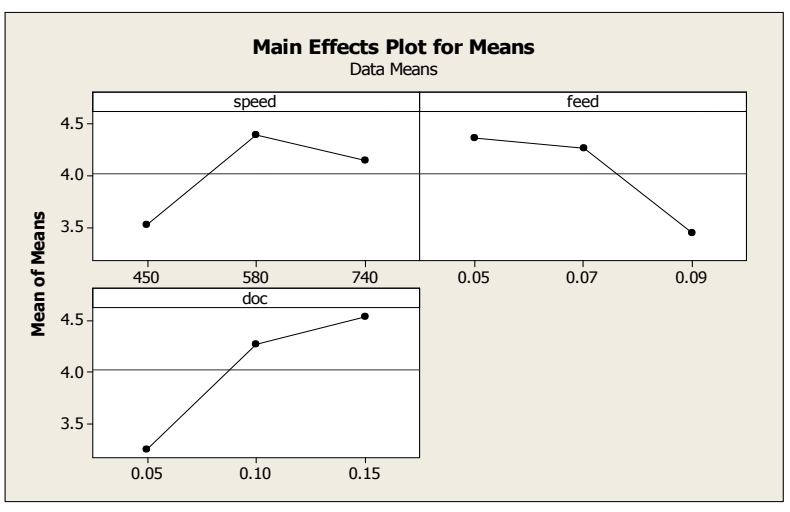

Fig 1: Plots of main effects for means for Surface roughness (Ra)

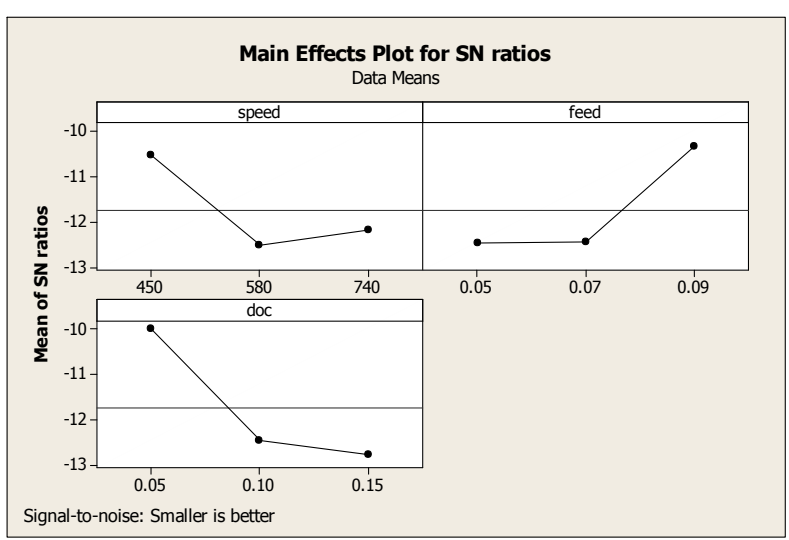

Fig 2: Plot of S/N ratio for Surface roughness (Ra)

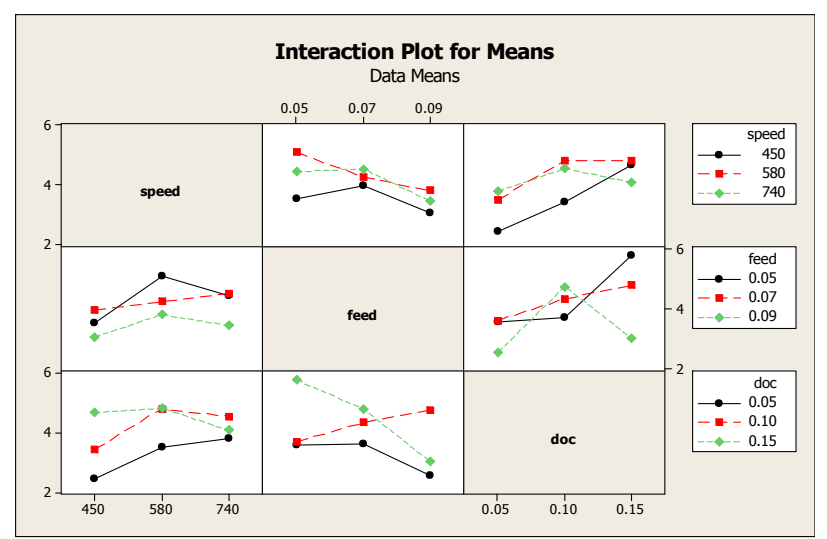

Fig 3: Plot of Interaction data means for Surface roughness (Ra)

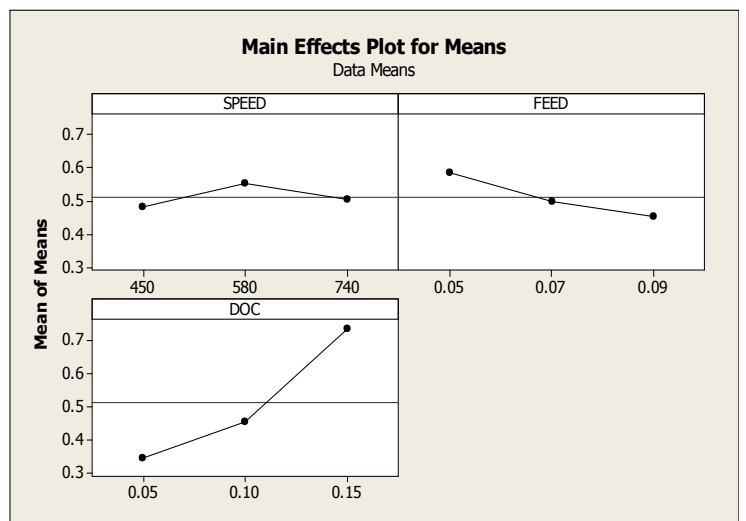

Fig 4: Plots of main effects for means for Material removal rate 


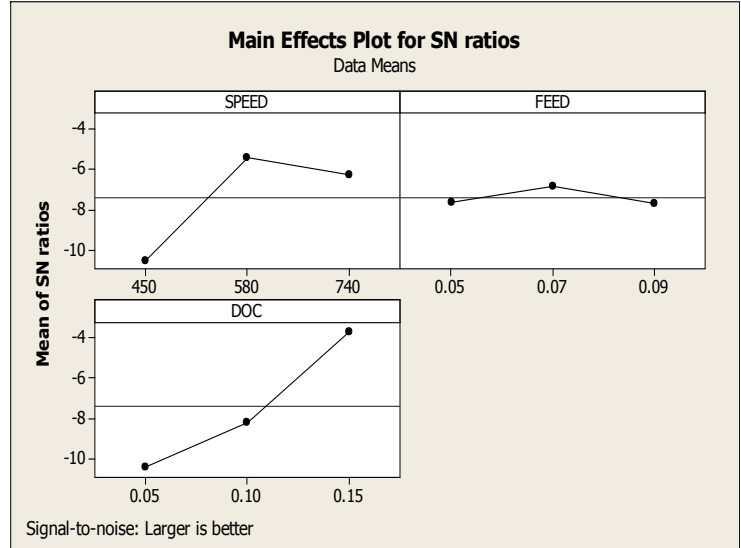

Fig 5: $\mathrm{S} / \mathrm{N}$ ratio for Material removal rate (MRR)

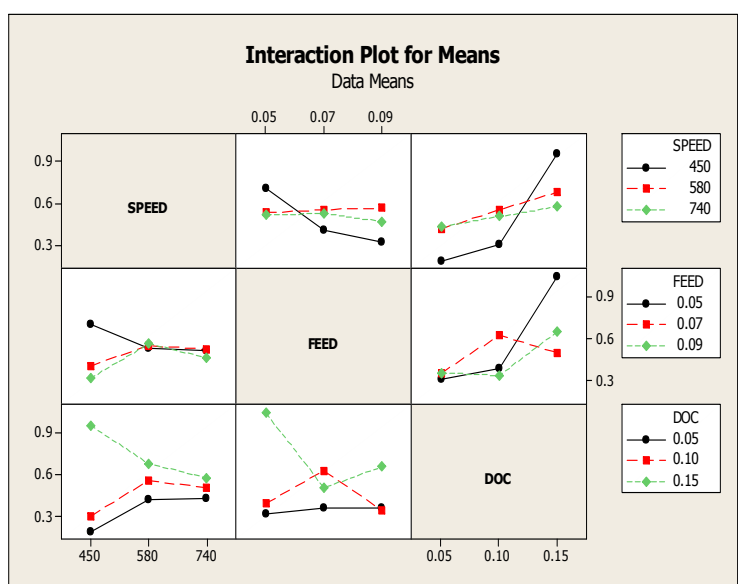

Fig 6: Interaction data means for Material removal rate (MRR)

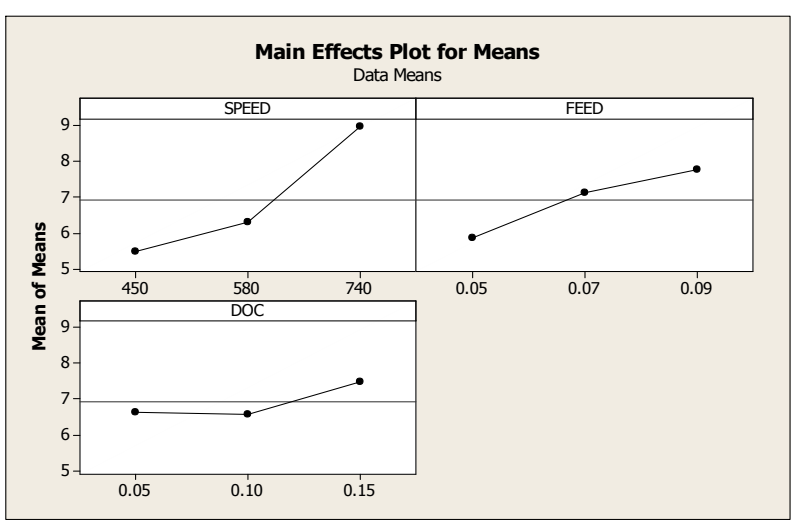

Fig 7: Plots of main effects for means for Power Consumption (PC)

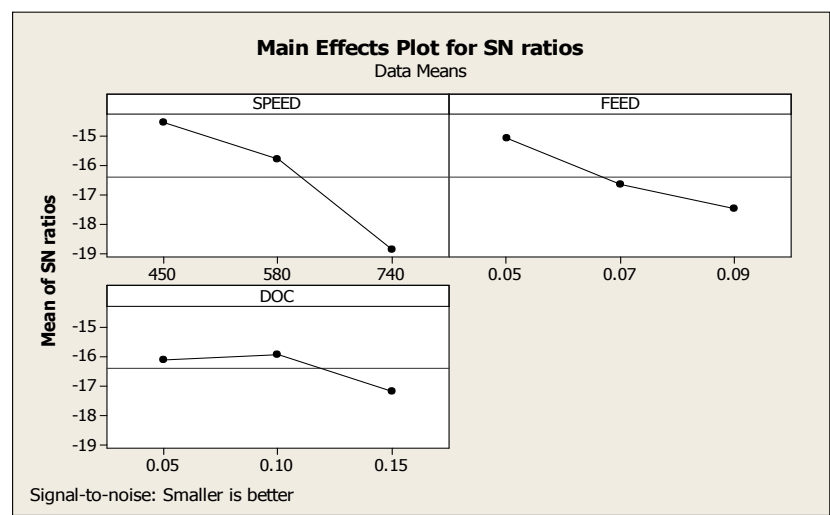

Fig 8: Plot of $\mathrm{S} / \mathrm{N}$ ratio for Power Consumption

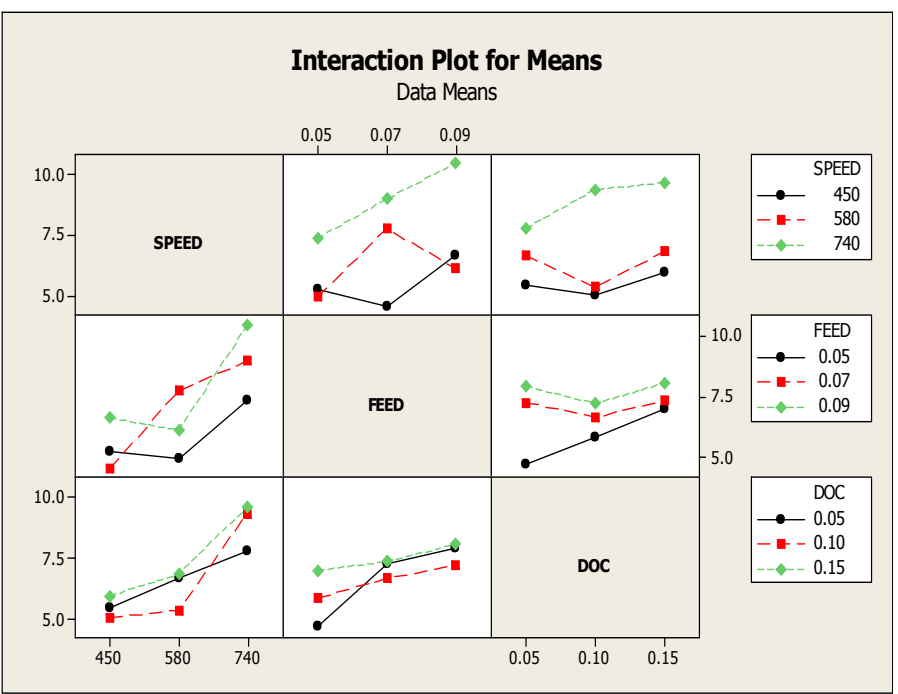

Fig 9: Interaction data means for Power Consumption (PC)

\section{CONCLUSIONS}

The results obtained in this study lead to conclusions for turning of AISI 4340 after conducting the experiments and analyzing the resulting data.

(1) From the results obtained by experiment, the influence of surface roughness (Ra), Material Removal Rate (MRR) and Power Consumption (PC) by the cutting parameters like speed, feed, DOC is

a) The feed rate has the variable effect on surface Roughness, cutting speed and depth of cut an approximate decreasing trend.

b) Cutting speed, feed rate and depth of cut for Material Removal Rate have increasing trend.

c) Power Consumption is increase with increase in cutting speed, feed rate and depth of cut.

(2) Taguchi method is applied for optimization of cutting Parameters 


\begin{tabular}{|l|c|l|l|}
\hline Responses & \multicolumn{3}{|c|}{ Input parameters } \\
\cline { 3 - 4 } & Speed(rpm) & $\begin{array}{l}\text { Feed(mm/ } \\
\text { rev) }\end{array}$ & $\begin{array}{l}\text { DOC(m } \\
\text { m) }\end{array}$ \\
\hline Ra (min) & $\mathbf{5 8 0}$ & $\mathbf{0 . 0 5}$ & $\mathbf{0 . 1 5}$ \\
\hline MRR(max) & $\mathbf{5 8 0}$ & $\mathbf{0 . 0 7}$ & $\mathbf{0 . 1 5}$ \\
\hline PC (min) & $\mathbf{7 4 0}$ & $\mathbf{0 . 0 9}$ & $\mathbf{0 . 1 5}$ \\
\hline
\end{tabular}

(3) Analysis of Variance (ANOVA) is done and found that it shows The depth of cut has great influence for the Response surface roughness (31.78\%), Speed has great Influence for the response Material removal rate (55.56\%), Depth of cut has great influence for the Response Power consumption (66.75\%).

(4) The interaction of cutting parameters is also studied for the three responses Ra, MRR and PC as follows

\begin{tabular}{|l|c|c|c|}
\hline Responses & \multicolumn{3}{|c|}{ INTERACTIONS (\%) } \\
& S x F & S x D & F x D \\
\hline Ra & 1.31 & 10.05 & 25.71 \\
\hline MRR & 8.27 & 18.67 & 9.46 \\
\hline PC & 1.98 & 4.51 & 2.75 \\
\hline
\end{tabular}

\section{REFERENCES}

[1] Nikunj R Modh, G. D. Mistry, K. B. Rathod/ International Journal of Engineering Research and Applications ,Vol. 1, Issue 3, pp.483-489.

[2] Mahendra korat, Neeraj Agarwal, Optimization of different Machining parameters of En 24 Alloy steel in CNC Turning by use of Taguchi method". International journal of engineering research and application. ISSN: 2248-9622.

[3] Ashok kumar sahoo and Bidyadhar sahoo/ International Journal of Industrial Engineering and computations 2 (2011) 819-830.

[4] B.Y.Lee, H.S.Liu Y.S.Tarng/Journal of Material Processing Technology 74 (1998) 149-157.

[5] Adnan Jameel , Mohamad Minhat and Md.Nizam/International Journal of Scientific and Research Publications, volume 3, Issue 5, May 2013.

[6] Ruben Phipon and B.B.Pardhan/IOSR Journal of engineering /Volume 2, Isuue 9 (september2012), PP106-115.

[7] H.M.Somashekara and Dr.N.Lakshmana Swamy/ International Journal of Engineering Science and Technology/ Volume 4 No.5 May 2012.
[8] Ciftci I., 2006. Machining of austenitic Stainless steels using CVD multi-layer coated cemented carbide tools, Tribology International, Vol.39, No. 6, pp. 565569.

[9] Raju Shrihari Pawade and Suhas S. Joshi., 2011. Multiobjective optimization of surface roughness and cutting forces in highspeed turning of Inconel 718 using Taguchi grey relational analysis (TGRA), International Journal of Advanced Manufacturing Technology, DOI 10.1007/s00170-011-3183-z.

[10] Gusri A.I., Che Hassan C.H., Jaharah A.G., Yanuar B.1, Yasir A.1, Nagi A, Application Of Taguchi method in Optimizing Turning Parameters of Titanium Alloy, Seminar on Engineering Mathematics, 2008 Engineering Mathematics Group.

[11] Farhad Kolahan, Mohsen Manoochehri, Abbas Hosseini, "Simultaneous Optimization of Machining Parameters and Tool Geometry Specifications in Turning Operation of AISI1045 Steel," World Academy of Science, Engineering and Technology 74 2011.

[12] Sijo M.T, Biju.N, "Taguchi Method for Optimization of Cutting Parameters in Turning Operations," Proc. of. Int. Conf. on Advances in Mechanical Engineering 2010.

[13] S.R.DAS, R.P.NAYAK,D.DHUPAL/International Journal of Lean Thinking Volume3, Issue 2(December 2012). 